\title{
Morfofisiologia e produção do algodoeiro herbáceo irrigado com águas salinas eadubado com nitrogênio
}

\author{
João Batista dos Santos, Hans Raj Gheyi, Geovani Soares de Lima, \\ Diego Azevedo Xavier, Lourival Ferreira Cavalcante, Cruz Ramón Marenco Centeno
}

Universidade Federal de Campina Grande, Campina Grande, PB, Brasil.

*Autor correspondente, e-mail: agrosantos@hotmail.com

\section{Resumo}

As altas concentrações de sais encontradas nas águas de irrigação em regiões semiáridas acarretam em alterações no crescimento e desenvolvimento das culturas, alem de promover a formação de solos halomórficos. Neste contexto, propôs-seavaliar amorfofisiologia e a produção do algodoeiro herbáceo colorido BRS Topázio, irrigado com águas de diferentes salinidades e adubado com nitrogênio em solo salino-sódico. O experimento foi conduzido em um Neossoloquartzarênicoeutrófico de textura arenosa no município de Campina Grande, Paraíba, utilizando-seo delineamento experimental inteiramente casualizado em esquema fatorial $5 \times 5$, com três repetições, sendo cinco níveis de salinidade da água de irrigação $\left(0,7 ; 2,7 ; 4,7 ; 6,7\right.$ e 8,7 dS $\mathrm{m}^{-1}$ a $25^{\circ} \mathrm{C}$ ) e cinco doses de nitrogênio (40; 60; 80; 100 e 120 mg de $\mathrm{N} \mathrm{kg}^{-1}$ de solo).A interação salinidade e nitrogênio não exerceu efeitos no crescimento do algodoeiro. A taxa de crescimento absoluto referente à altura, diâmetro de caule e área foliar diminuiu com incremento na condutividade elétrica da água de irrigação, sendo a área foliar a variável mais afetada. O número de capulhos e a produção de algodão em caroço por planta reduziu com o aumento da salinidade da água e aumentoucom incremento da adubação nitrogenada.

Palavras-chave: condutividade elétrica, Gossipium hirsutum L. r. latifolium H. nitrogênio

\section{Morphophysiology and production of cotton irrigated with saline waters and fertilized with nitrogen}

\begin{abstract}
The high salt concentrations found in irrigation water in semi-arid regions lead to changes on crops growth and development and can lead to halomorphicsoils formation. In this context, it was proposed to evaluate the morphophysiology and production of colored herbaceous cotton BRS Topaz fertilized with nitrogen under a saline-sodic soil and submitted to the irrigation with different salinities water. The experiment was conducted in an eutrophic sandy quartzarênico neossol in the municipality of Campina Grande, Paraíba, Brazil, adopting a completely randomized design in $5 \times 5$ factorial with three repetitions, with five salinity levels of the the irrigation water $(07 ; 2.7 ; 4.7 ; 6.7$ and $8.7 \mathrm{dS} \mathrm{m} \mathrm{m}^{-1}$ at $25^{\circ} \mathrm{C}$ ) and five levels of nitrogen (40;60;80; 100 and $120 \mathrm{mg}$ of $\mathrm{N} \mathrm{kg}^{-1}$ ). Regarding to cotton growing, no oeffect was observed for the interaction between salinity and nitrogen doses. The absolute growth rate for height, stem diameter and leaf area decreased with an increase in the irrigation water electrical conductivity, being leaf area the most affected variable. The number of bolls and the cotton seed production per plant decreased with the salinity increase and increased with an increase of nitrogen fertilization.
\end{abstract}

Keywords: Electrical conductivity, Gossipium hirsutum L. r. latifolium H. Nitrogen 
Introdução

A cotonicultura brasileira exercegrande importância socioeconômica para $\bigcirc$ País, especialmente nasregiões Nordeste, Centro Oeste e Sudeste, onde se situam as maiores áreas cultivadas (Oliveira et al., 2009).Apesar de ser tolerante aos sais, pode sofrer queda de produção nas áreas semiáridas do Brasil onde o nível salino das águas pode transformar áreas produtivas em áreas sem função agrícola, ao longo do tempo(Furtado et al., 2007; Lopes \& Silva, 2010) bem como reduções substanciais no crescimento e na produção quando exposta à condição de estresse salino da água ou do solo (Oliveira et al., 2008).

Nas regiões semiáridas do Nordeste brasileiro, a prática dairrigação consiste em uma das tecnologias utilizadas para garantir - desenvolvimento e produção das culturas, minimizando os efeitos nocivos das secas periódicas e da irregularidade das precipitações (Oliveira et al., 2012). Contudo, nestas áreas é comum a utilização de fontes de água, com alta concentração de sais, sobretudo de $\mathrm{Na}^{+}$,que comprometem a sustentabilidadeedáfica dos solos e a capacidade produtiva das plantas (Neves et al., 2009).

A presença de sais na água de irrigação reflete em alterações no potencial osmótico, na toxicidade dos íons e no desequilíbrio nutricional das plantas (Ferreira et al., 2007), promovendo modificações nas funções fisiológicas e bioquímicas, resultando em distúrbios nas relações hídricas e alterações na absorção e na utilização de nutrientes essenciais para as plantas, retardando seu crescimento e reduzindo a produção (Amorim et al., 2010). Todavia, nas plantas a intensidade desses efeitos dependem de outros fatores, como espécie, cultivar, tipos de sais, intensidade e duração do estresse, manejo cultural e da irrigação, condições edafoclimáticas e adubação (Munns \& Tester, 2008).

Assim, o mecanismo mais importante para regular o estresse osmótico, talvez seja a absorção seletiva de íons, pois plantas tolerantes possuem a capacidade de retirar nutrientes essenciais da solução salina, onde a concentração de íons não essenciais é maior
(Fageria, 1989).

Deste modo, destaca-se o suprimento nutricional com nitrogênio, em razão domacronutriente participar da estrutura da planta, sendo componente de aminoácidos, proteínas, enzimas, RNA, DNA, ATP, clorofila, dentre outras moléculas, está diretamente relacionado às características ligadas ao crescimento da planta (Chaves et al., 2011). Além disso, estudos têm demonstrado que existem evidências de competição na absorção entre nitrato e cloreto, de modo que um aumento na concentração de nitrato na zona radicular pode inibir uma maior absorção de cloreto pela planta (Flores et al., 2002)

Neste contexto, objetivou-se com este trabalho avaliar a morfofisiologia e a produção do algodoeiro herbáceo colorido BRS Topázio, irrigado com águas de diferentes salinidades e submetido a adubação nitrogenada em solo salino-sódico.

\section{Material e Métodos}

O experimento foi conduzido durante 0 período de setembro de 2012 a janeiro de 2013 em casa de vegetação pertencente á Unidade Acadêmica de Engenharia Agrícola (UAEAg), da Universidade Federal de Campina Grande - UFCG, município de Campina Grande, Estado da Paraíba-PB, nas coordenadas geográficas 7015'18" de latitude Sul e 3552' $28^{\prime \prime}$ de longitude Oeste do Meridiano de Greenwich e na altitude de $550 \mathrm{~m}$.

O delineamento experimental utilizado foi o inteiramente casualizado em esquema fatorial $5 \times 5$, com três repetições, referentes aos níveis de salinidade da água de irrigação, expressos pelos valores de condutividade elétrica (CEa)de 0,$7 ; 2,7 ; 4,7 ; 6,7$ e $8,7 \mathrm{dS} \mathrm{m}^{-1}$, preparados mediante adição de cloreto de sódio ( $\mathrm{NaCl})$ à água do sistema de abastecimento local (CEa de $0,7 \mathrm{dS} \mathrm{m}^{-1}$ ) e cinco doses de nitrogênio (40;60; 80; 100 e $120 \mathrm{mg}$ de $\mathrm{Nkg}^{-1}$ de solo).

Cada unidade experimental foi constituída de um vaso plástico com capacidade de $100 \mathrm{~L}$ no qual foramacondicionados $90 \mathrm{~kg}$ de solo tipo Neossoloquatzarênico(Tabela 1). Em referência aos tratamentos de nitrogênio, a adubação foi aplicada um terço no semeio 
e dois terços em duas parcelas iguais aos 20 e 40 dias após a semeadura (DAS). A adubação fosfatada na forma de superfosfato simplescorrespondeu a $300 \mathrm{mg}$ de $\mathrm{P}_{2} \mathrm{O}_{5} \mathrm{~kg}^{-1} \mathrm{de}$ solo, aplicada em fundação no dia do semeio e a adubação potássica na forma de cloreto de potássio (150 mg de $\mathrm{K}_{2} \mathrm{O} \mathrm{kg}^{-1}$ de solo) foi dividida em três aplicações de maneira idêntica a nitrogênio.

As irrigações foram realizadas

Tabela 1. Características físico-químicas medias na camada de $0-20 \mathrm{~cm}$ de profundidade do solo coletado no interior dos vasos antes da aplicação dos tratamentos.

\begin{tabular}{|c|c|c|c|}
\hline Características químicas & Valores & Características físicas & Valores \\
\hline $\mathrm{pH}$ & 6,15 & Areia $\left(\mathrm{g} \mathrm{kg}^{-1}\right)$ & 858,1 \\
\hline$M O\left(g ~ k g^{-1}\right)$ & 15,7 & Silte $\left(\mathrm{g} \mathrm{kg}^{-1}\right)$ & 94,1 \\
\hline$P\left(\mathrm{mg} \mathrm{dm}^{-3}\right)$ & 65,3 & Argila $\left(\mathrm{g} \mathrm{kg}^{-1}\right)$ & 47,8 \\
\hline $\mathrm{Ca}^{2+}\left(\mathrm{cmol}_{\mathrm{c}} \mathrm{kg}^{-1}\right)$ & 2,96 & Classificação & Areia franca \\
\hline $\mathrm{Mg}^{2+}\left(\mathrm{cmol}_{\mathrm{c}} \mathrm{kg}^{-1}\right)$ & 1,39 & Ds $\left(\mathrm{kg} \mathrm{dm}^{-3}\right)$ & 1,45 \\
\hline $\mathrm{K}^{+}\left(\mathrm{cmol}_{\mathrm{c}} \mathrm{kg}^{-1}\right)$ & 0,5 & $\mathrm{Dp}\left(\mathrm{kg} \mathrm{dm^{-3 } )}\right.$ & 2,73 \\
\hline $\mathrm{Na}^{+}\left(\mathrm{cmol}_{\mathrm{c}} \mathrm{kg}^{-1}\right)$ & 2,37 & $\mathrm{Pt}\left(\mathrm{m}^{3} \mathrm{~m}^{3}\right)$ & 0,46 \\
\hline $\mathrm{Al}^{3+}\left(\mathrm{cmol}_{\mathrm{c}} \mathrm{kg}^{-1}\right)$ & 0 & Umidadenatural(\%) & 0,5 \\
\hline $\mathrm{H}^{+}\left(\mathrm{cmol}_{\mathrm{c}} \mathrm{kg}^{-1}\right)$ & 0,73 & Ucc - 0,010MPa (\%) & 7,04 \\
\hline $\mathrm{SB}\left(\mathrm{cmol}_{\mathrm{c}} \mathrm{kg}^{-1}\right)$ & 7,22 & Upmp - 1,5 MPa (\%) & 2,99 \\
\hline CTC $\left(\mathrm{cmol}_{\mathrm{c}} \mathrm{kg}^{-1}\right)$ & 7,95 & & \\
\hline$\vee(\%)$ & 90,8 & & \\
\hline CEes $\left(\mathrm{d} S \mathrm{~m}^{-1}\right)$ & 7,22 & & \\
\hline PST (\%) & 29,8 & & \\
\hline Classificação & Salino sódico & & \\
\hline
\end{tabular}

manualmente com frequência de dois dias aplicando-se um volume de água calculado pela diferença entre o volume de água aplicado e o volume drenado (VI = VA - VD) na irrigação anterior somada a uma lâmina de lixiviação de $10 \%$. Apesar da equação não considerar a evaporação do solo e nem a evapotranspiração das plantas, essa metodologia é adequada para a lixiviação dos sais do ambiente radicular e promover o crescimento das plantas sob irrigação com água de salinidade crescente(MESQUITA et al., 2012;DINIZ et al., 2013).As irrigações foram suspensas quando $70 \%$ dos capulhos estavam abertos.

A avaliação do crescimento do algodoeiro foi realizada, a cada 20 dias, a partir dos 30 até os 90 dias após semeadura (DAS), medindo-se a altura de planta, o diâmetro de caule e a área foliar, estimando-se esta última através de medidas lineares nas folhas, apartir da equação proposta porWendt (1967)log y $=0,006+1,863 \log x$,em que y é área foliar da folha $\left(\mathrm{cm}^{2}\right)$ e $x$ o comprimento da nervura principal da folha $(\mathrm{cm})$. A área foliar por planta foi determinada pelo somatório da área foliar de cada folhado algodoeiro.
A altura de planta foi medida a partir do colo até o meristema apical da planta. $\bigcirc$ diâmetro caulinar foi medido em média $3,0 \mathrm{~cm}$ acima da superfície do solo.A partir dos valores médios de altura de planta e diâmetro de caule foram estimadas as taxas de crescimento absoluto (TCA), sendo obtida conforme a metodologia contida em Benincasa (2003) expressa pela Eq. 1.

$$
\mathrm{TCA}=\frac{\mathrm{v}_{2}-\mathrm{v}_{1}}{\mathrm{t}_{2}-\mathrm{t}_{1}}
$$

em que:

$v_{1}$ - Variável que se deseja calcular a taxa de crescimento no tempo $t_{1}$; em dias

$v_{2}$ - Variável que se deseja calcular a taxa de crescimento no tempo $t_{2}$; em dias

A colheita foi realizada manualmente e numa única vez, aos 130 dias após a semeadura. Os capulhos foram acondicionados em sacos de papel previamente identificados conforme tratamentos. Para avaliação daprodução foram consideradoso número de capulhose a produção de algodão em caroço por planta.

Os resultados foram submetidos à análise de variância pelo teste ' $F$ ' ao nível de 0,01 e 0,05 de probabilidade e nos casos 
de efeitos significativos, realizou-se análise de regressão utilizando o software estatístico SISVAR (FERREIRA, 2011).Na análise morfofisiológica ao longo do tempo se considerou apenas regressão de até segundo grau em virtude de explicação biológica dos efeitos dos fatores estudados. Diante da heterogeneidade dos dados percebidos através dos valores de coeficiente de variação apresentados referente as algumas épocas de avaliação, foi necessário realizar análise exploratória dos mesmos, sendo transformadosporlog $x$.

\section{Resultados e Discussão}

A partir dos resumo das análise de variância (Tabela 2) constata-se que 0 crescimento do algodoeiro herbáceo BRS Topázio, em altura, em diâmetro e em área foliar não foi influenciado pela interação salinidade da água $x$ doses de nitrogênio e nem pelo efeito isolado da aplicação de nitrogênio. Por outro lado, o aumento do teor salino das águas exerceu influência significativa no crescimento em altura das plantas.

Tabela 2. Resumo das análises de variância e regressão para altura de planta, diâmetro de caule e área foliar de algodão herbáceo BRS Topázio, aos 30, 50, 70 e 90 dias após a semeadura (DAS), em função da salinidade da água de irrigação e da adubação nitrogenada.

\begin{tabular}{|c|c|c|c|c|c|}
\hline \multirow{3}{*}{ Fonte de Variação } & \multirow{3}{*}{ GL } & \multicolumn{4}{|c|}{ Quadrados médios } \\
\hline & & \multicolumn{4}{|c|}{ - } \\
\hline & & 30 & 50 & 70 & 90 \\
\hline Altura de planta & & \# & \# & & \\
\hline Salinidade (S) & 4 & $0,073^{*}$ & $0,071^{* *}$ & $5591,713^{* *}$ & $8691,247^{* *}$ \\
\hline Reg. Linear & 1 & $0,274^{* *}$ & $0,277^{* *}$ & $21720,167^{* *}$ & $31566,507^{* *}$ \\
\hline Reg. Quadrática & 1 & $0,004^{\text {ns }}$ & $0,005^{\mathrm{ns}}$ & $39,433^{\text {ns }}$ & $832,019^{*}$ \\
\hline Desvio & 1 & $0,007^{\text {ns }}$ & $0,001^{\mathrm{ns}}$ & $303,627^{\text {ns }}$ & $1183,230^{* *}$ \\
\hline Nitrogênio (N) & 4 & $0,016^{\mathrm{ns}}$ & $0,008^{\text {ns }}$ & $79,380^{\text {ns }}$ & $104,647^{\text {ns }}$ \\
\hline Interação $S \times N$ & 16 & $0,025^{\mathrm{ns}}$ & $0,012^{\text {ns }}$ & $221,722^{\text {ns }}$ & $223,063^{\text {ns }}$ \\
\hline Resíduo & 50 & 0,023 & 0,012 & 180,760 & 140,396 \\
\hline $\mathrm{CV}(\%)$ & - & 12,02 & 6,67 & 15,61 & 12,01 \\
\hline \multicolumn{6}{|c|}{ Diâmetro do caule\#\# } \\
\hline Salinidade (S) & 4 & $0,003^{\text {ns }}$ & $0,001^{\mathrm{ns}}$ & $16,061^{* *}$ & $87,640 * *$ \\
\hline Reg. Linear & 1 & $0,000^{\text {ns }}$ & $0,000^{\text {ns }}$ & $61,696^{* *}$ & $270,14^{* *}$ \\
\hline Reg. Quadrática & 1 & $0,002^{\text {ns }}$ & $0,000^{\text {ns }}$ & $0,149^{\text {ns }}$ & $39,88^{* *}$ \\
\hline Desvio & 1 & $0,006^{\mathrm{ns}}$ & $0,001^{\mathrm{ns}}$ & $1,199^{\text {ns }}$ & $20,27^{* *}$ \\
\hline Nitrogênio (N) & 4 & $0,005^{\mathrm{ns}}$ & $0,009^{\text {ns }}$ & $0,677^{\text {ns }}$ & $1,609^{\text {ns }}$ \\
\hline Interação (S x N) & 16 & $0,009^{\text {ns }}$ & $0,005^{\text {ns }}$ & $1,762^{\mathrm{ns}}$ & $1,968^{\text {ns }}$ \\
\hline Resíduo & 50 & 0,006 & 0,007 & 2,461 & 1,821 \\
\hline $\mathrm{CV}(\%)$ & - & 15,72 & 9,90 & 15,73 & 11,09 \\
\hline \multicolumn{6}{|l|}{ Área foliar\#\#\#\# } \\
\hline Salinidade (S) & 4 & $0,006^{\mathrm{ns}}$ & $0,042^{\text {ns }}$ & $0,604^{* *}$ & $2,147^{* *}$ \\
\hline Reg. Linear & 1 & $0,018^{\text {ns }}$ & $0,147^{n s}$ & $2,264^{* *}$ & $3,691 * *$ \\
\hline Reg. Quadrática & 1 & $0,003^{\text {ns }}$ & $0,007^{n s}$ & $0,031^{\mathrm{ns}}$ & $2,249 * *$ \\
\hline Desvio & 1 & $0,001^{\mathrm{ns}}$ & $0,006^{n s}$ & $0,061^{\text {ns }}$ & $1,323^{* *}$ \\
\hline Nitrogênio (N) & 4 & $0,011^{\mathrm{ns}}$ & $0,075^{\text {ns }}$ & $0,045^{\text {ns }}$ & $0,006^{\text {ns }}$ \\
\hline Interação S x N & 16 & $0,031^{\text {ns }}$ & $0,036^{\mathrm{ns}}$ & $0,019^{\text {ns }}$ & $0,034^{\text {ns }}$ \\
\hline Resíduo & 50 & 0,018 & 0,042 & 0,044 & 0,029 \\
\hline $\mathrm{CV}(\%)$ & - & 5,68 & 6,38 & 5,76 & 4,82 \\
\hline
\end{tabular}

Pela referida tabela constatam-se efeitos significativos da salinidade sobre o crescimento em altura em todas as épocas avaliadas, enquanto no diâmetro caulinar e área foliar os efeitos dos sais das águas foram significativos a partir dos 70 dias após a semeadura (DAS). Isto se deve aos efeitos da salinidade da água e ao caráter salino-sódico do solo que antes da semeadura apresentava nível médio de salinidade $\left(\right.$ CEes $=7,22 \mathrm{dSm}^{-1}$ ) e elevado de sodicidade (PST $=29,8)$ como indicado na Tabela 1. Nobre et al. (2010) estudando a cultura do girassol cv. Embrapa 122/V-2000, também não verificaram efeito significativo da interação 
entre os fatores salinidade da água de irrigação e doses de nitrogênio sobre a altura das plantas (AP) e diâmetro caulinar(DC).

Pelos estudos de regressão (Figura 1A) constata-se que houve efeito linear e decrescente $(p<0,01)$ da salinidade da água de irrigação sobre o crescimento das plantas em altura comdiminuição de 3,$73 ; 3,68 ; 5,26$ e $5,53 \%$ por aumento unitário daCEa, respectivamente, aos 30, 50, 70 e 90 DAS. Verifica-se efeito menos agressivo dos sais nos primeiros 30 e 50 DASna altura das plantasem relação ao aumento da salinidade da água de irrigação, isto se deve ao fato do solo, apesar de ser salino sódico (Tabela 1) não comprometeu o crescimento das plantas nas respectivas idades, isto é, durante - crescimento inicial.Por outro lado, dos 70 aos e 90 DAS a curva apresenta maior declínio em relação ao incremento da condutividade

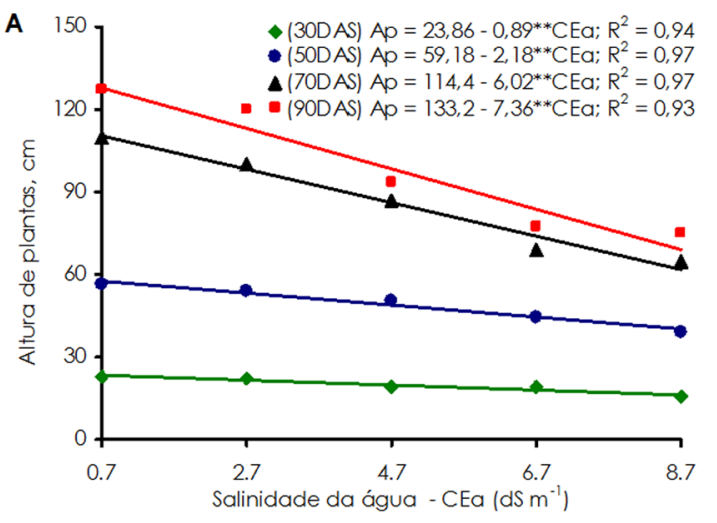

Figura 1. Altura de plantas aos 30,50, 70 e 90 DAS (A) e diâmetro de caule do algodoeiro herbáceo BRS Topázio, aos 70 e 90 DAS (B), em função da salinidade da água de irrigação.

Quanto ao diâmetro caulinar (Figura 1B), observa-se que osníveis salinos das águas de irrigação exerceram efeito significativo $(p<0,01)$ e negativoa partir dos 70 DAS do algodoeiro e o modelo de regressão que melhor se ajustouaos dados foi o linear decrescente com reduções de 0,32 e 0,71mmcorrespondentes asreduções de 2,79 e 4,58\%, respectivamente, por aumento unitário da condutividade elétrica da água de irrigação, aos 70 e 90 DAS (Figura 1B). Comportamento semelhante foi registrado também por Silva Junior et al. (2005), no algodoeiro BRS Verdesob irrigação com água de condutividade elétrica variando de 2,0 a 9,0 dS $\mathrm{m}^{-1}$, ao constatarem diminuição no diâmetro de caule de $3,23 \%$, por incremento unitário da condutividade elétrica da água aos 120 dias elétrica das águas.

Aredução na AP do algodoeiro BRS Topázio em consequência doaumento da CEa pode ser atribuída à menor absorção de águaprovocada pela diminuição no potencial osmótico da solução do solo (OLIVEIRA et at., 2012). Tais decréscimos caracterizam o efeito negativo dos sais sobre o crescimento do algodoeiro, fato tambémobservado por Jacome et al. (2003) ao constatarem redução da altura de plantas do algodoeiro herbáceo de fibra brancaavaliandocinco níveis de salinidade da água de irrigação(entre2,0 e 10,0 dS $\left.\mathrm{m}^{-1}\right)$. Siqueira et al. (2005) ao estudarem o crescimento do algodão herbáceo colorido sobre diferentes níveis de salinidade da água de irrigação (CEavariando de 2,0 a 9,5 dS $\mathrm{m}^{-1}$ ) também observaram declínio daAP.

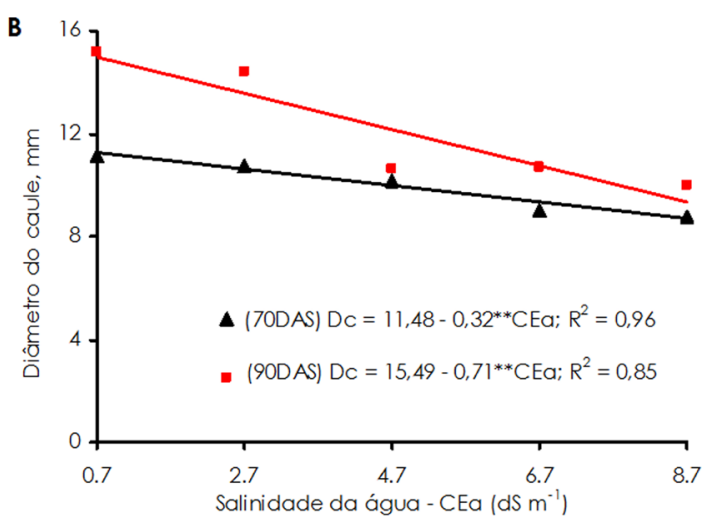

após o semeio, valor próximo dos constatados neste trabalho (Figura 1B).

O aumento da salinidade das águas, reduziu a área foliar do algodoeiroapartir dos 70 DAS, avaliada aos 70 e 90 DAS (Figura 2),os valores decresceram, respectivamente, de 7,92 e 9,55\%por aumento unitário da condutividade elétrica da água de irrigação. Ao se comparar os valores da área foliar aos 70 e 90 DAS, percebese que a redução é, em maior parte devida a crescente salinidade das águas, mas também é devida a abscisão das folhas adultas. Resultados semelhantes foram apresentados por Jácome et al. (2003) ao estudarem o crescimento de genótipos de algodoeiroherbáceo de fibra branca, em função da salinidade da água de irrigação entre 2,0 e 10,0 dS $\mathrm{m}^{-1}$ e por Siqueira 
et al. (2005) no crescimento do algodoeiro colorido marrom sob salinidade da água de irrigação de 2,0 a 9,5 dS $\mathrm{m}^{-1}$. Verificaram-se também modificações no limbo foliar como aspereza ao tato, folhas com coloração verde azulada e folhas amareladas. Segundo Maas\&
Hoffman (1977) plantas afetadas por sais, em geral, parecem normais, embora estejam atrofiadas e possam ter folhas de coloração verde escuro que,em muitos casos, são espessas e muito suculentas, nas espécies mais tolerantes à salinidade.

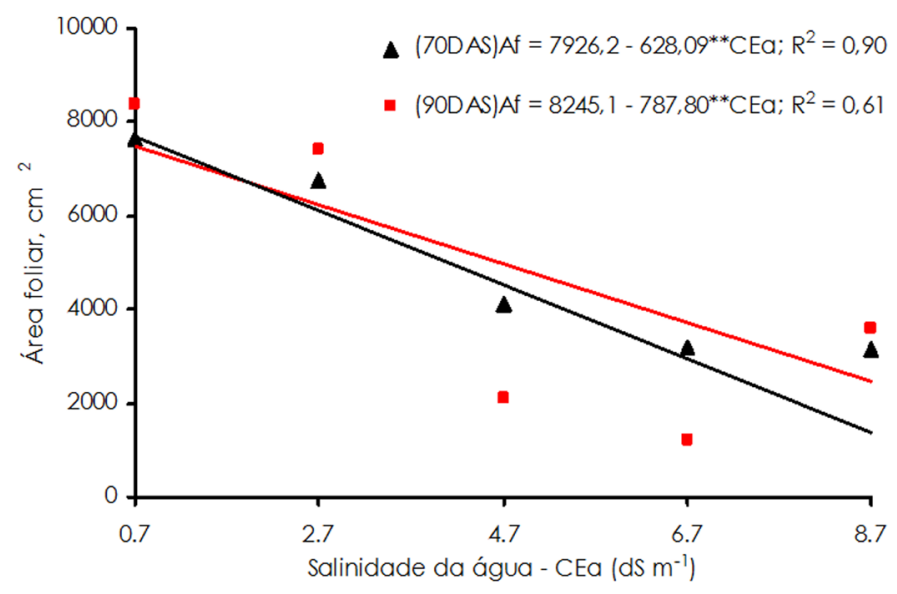

Figura 2. Área foliar do algodoeiro herbáceo BRS Topázio, em função da salinidade da água de irrigação, aos 70 e 90 dias após a emergência.

Pela Figura 3, verifica-se que as variáveis altura de planta, diâmetro do caulee área foliar avaliadas aos 30, 50, 70 e 90 DAS, apresentam valores que variaram com tempo e com a salinidade desde a semeadura(Tempo zero - 0 DAS) e 0,7 dS $\mathrm{m}^{-1}$, embora as diferenças entre os tratamentosvariaram em função do tempo e aumento da salinidade da água de irrigação a partir dos 50 DAS. As plantas (Figura 3A) cresceram em alturaaté os 90 DAS, quando irrigadas com águas de até $2,7 \mathrm{dS} \mathrm{m}^{-1}$, mas

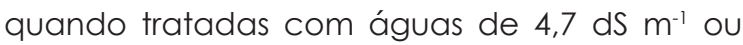
superior, o crescimento em altura aumentou da semeadura até os 70 DAS,sofrendo redução do crescimento ao longo do resto do ciclo.

Quanto aos resultados de taxa de crescimento absoluto em altura de plantas (TCAap), observa-se (Figura 3B) que os valores máximos foram obtidos no período de 51 a 70 dias após a semeadura. No mesmo período a TCAapsofreu redução de 2,63 para $1,11 \mathrm{~cm}$ dia 'entre as plantas irrigadas com água de menor $\left(0,7 \mathrm{dS}^{-1}\right)$ e de maior nível salino $\left(8,7 \mathrm{dS}^{-1}\right)$, causando redução de $57,63 \%$.

Quanto à evolução do diâmetro do caule (Figura $3 \mathrm{C}$ ), observa-se aumento até aos 90 DAS, referente ao nível salinode até $2,7 \mathrm{dS} \mathrm{m}^{-1}$, como registrado para a altura de planta a partir dos 70 DAS, mas foi reduzido nas plantas irrigadas com águas de maior salinidade. Resultados semelhantes foram obtidos por siqueira et al. (2005) ao estudarem o crescimento do algodoeiro colorido marrom irrigado com águas de salinidade variando de 2,0 a 9,5 $\mathrm{dS} \mathrm{m}^{-1}$.

A taxa de crescimento absoluto em diâmetro caulinar dos 51 ao 70 DAS diminuiu com o aumento da salinidade da água de irrigação de 0,21 para0,08 $\mathrm{mmdia}^{-1}$ (Figura 3D) e resultou numa perda de $61,91 \%$ entre as plantas irrigadas

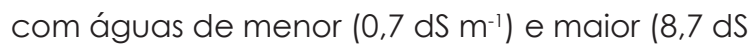
$\mathrm{m}^{-1}$ ) condutividade elétrica.

A área foliar (Figura 3E) aumentou até aos 70 DAS, quando as plantas foram irrigadas com água de CEa até 2,7 dS $\mathrm{m}^{-1}$, acima desse valor houve redução. Quando as plantas foram submetidas aos demais níveis de salinidade a área foliar aumentou até os 60 DAS, aproximadamente, e apartir dos 70 DAS registraram-se declínios. A redução na área foliar foi causada pela salinidade e também à abscisãodas folhas adultas.A diminuição da área foliar das plantas sob condições de estresse salino foi verificada também em outras culturas, como bananeira, cultivada em solo salinizado artificialmente (Silva Júnior et al., 2012), mamona (Santos et al., 2013), girassol (Oliveira et al., 2010) e meloeiro (Porto Filho et al., 2006). 

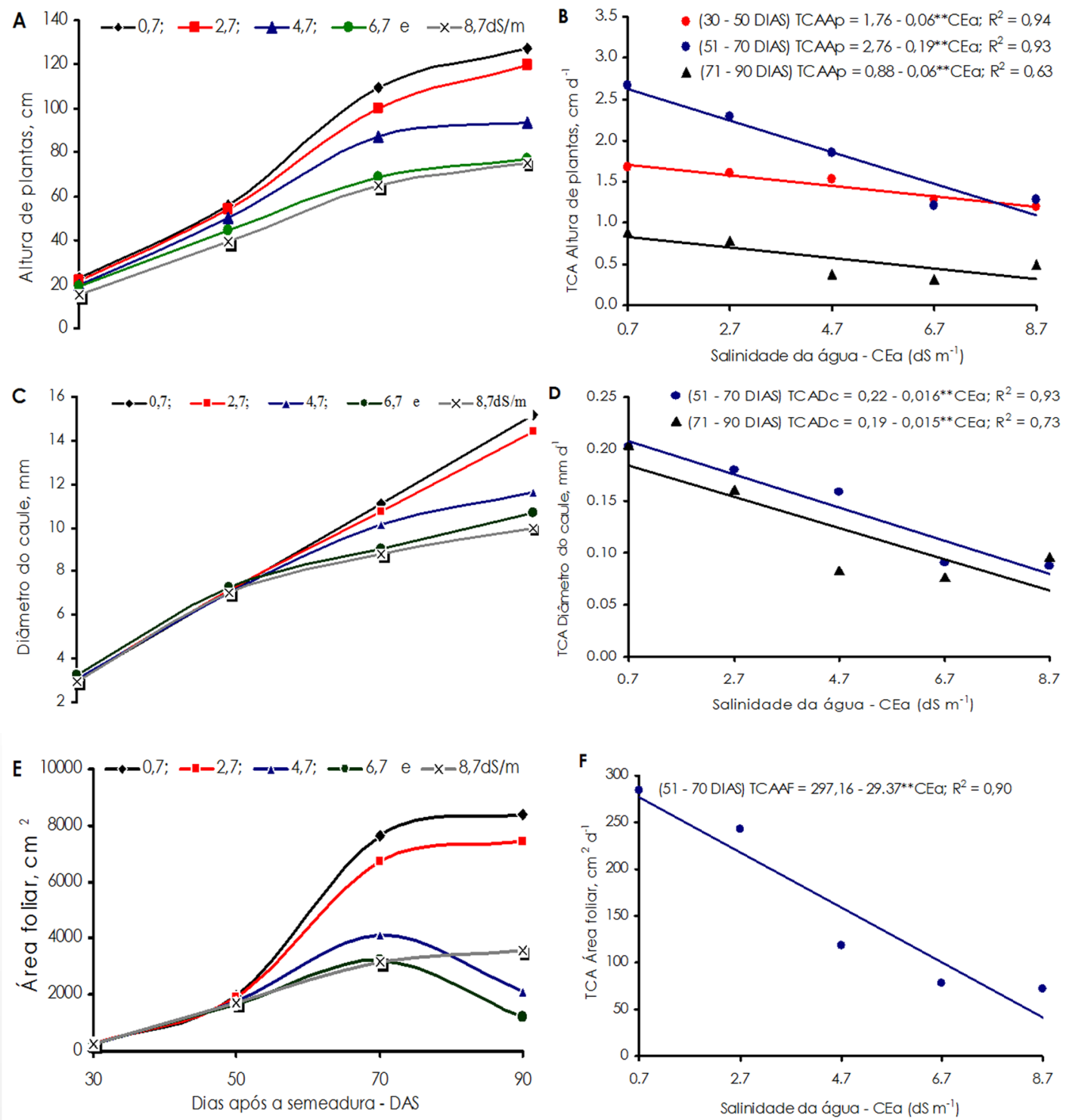

Figura 3. Evolução da altura, diâmetro e área foliar (A, C e E) e taxa de crescimento absoluto em altura, diâmetro e área foliar(B, D e F), do algodoeiro herbáceo BRS Topázio, aos 30, 50, 70 e 90 DAS, em função daidade das plantas e salinidade da água de irrigação.

Quanto aos resultados da taxa de crescimento absoluto em área foliar (TCAaf), observa-se (Figura 3F) que de forma semelhante à alturade plantas e diâmetro de caule, os valores máximos também corresponderam ao período de 51 a 70 DAS. Nesse intervalo, a TCAaf máxima medida foi de $276,6 \mathrm{~cm}^{2} \mathrm{dia}^{-1}$ nas plantas irrigadas

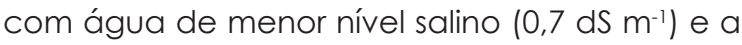
mínima foi $41,64 \mathrm{~cm}^{2} \mathrm{dia}^{-1}$ para o maior nível salino $\left(8,7 \mathrm{dS}^{-1}\right)$, causando redução de $84,95 \%$ na TCAaf no referido período. Comparativamente, a ordem dos efeitos degenerativos da salinidade da água no comportamento morfológico do algodoeiro herbáceo BRS Tapazio foi área foliar>diâmetro do caule>altura das plantas e expressa maior sensibilidade das folhas à salinidade. Essas respostas estão em consonância com Munns \& Tester (2008) ao afirmarem que os distintosórgãos das plantas podem responder diferenciadamente à ação dos sais.

Pelos resumos das análises de variânciaa interaçãoentre os níveis de salinidade da água de irrigação e doses de nitrogênio exerceu efeito significativos sobre onúmero de capulhos e produção de algodão em caroço por planta (Tabela 3). Esse comportamento estatístico da produção diverge do registrado para a morfologia das plantas em que a interação salinidade $x$ nitrogênio não interferiu significativamente no crescimento das plantas. 
Tabela 3. Resumo das análises de variância e regressão para número de capulhos por planta (NCP) e produção (PROD) de algodão herbáceo BRS Topázio em caroço aos 130 DAS, em função da salinidade da água de irrigação e da adubação nitrogenada.

\begin{tabular}{lccc}
\hline \multirow{2}{*}{ Fonte de Variação } & \multirow{2}{*}{ GL } & \multicolumn{2}{c}{ Quadrados médios } \\
\cline { 3 - 4 } & & NCP & PROD \\
\hline Salinidade (S) & 4 & $4977,57^{* *}$ & $119836,89^{* *}$ \\
Reg. Linear & 1 & $14701,50^{* *}$ & $336393,18^{* *}$ \\
Reg. Quadrática & 1 & $2407,24^{* *}$ & $56783,11^{* *}$ \\
Desvio & 1 & $1400,76^{* *}$ & $43084,14^{* *}$ \\
Nitrogênio (N) & 4 & $252,43^{* *}$ & $7207,35^{* *}$ \\
Reg. Linear & 1 & $962,67^{* *}$ & $26749,13^{* *}$ \\
Reg. Quadrática & 1 & $4,88^{\text {ns }}$ & $1,37^{\text {ns }}$ \\
Desvio & 1 & $21,09^{\text {ns }}$ & $1039,46^{\text {ns }}$ \\
Interação S X N & 16 & $124,21^{* *}$ & $3868,79^{* *}$ \\
Resíduo & 50 & 19,01 & 728,04 \\
\hline CVV(\%) & - & 15,14 & $16,74^{-1}$ \\
\hline CV coeficiente de variação; ns, ${ }^{* *}$ e respectivamente, não significativo, significativo a $p<0,01 \mathrm{e} p<0,05$ &
\end{tabular}

O número de capulhos por planta diminuiu com o aumento da salinidade da água de irrigação, mas aumentou em função do incremento da adubação nitrogenada (Figura 4). O menor número de capulhos por planta (14,8 capulhos) foi obtido quando o ponto de equilíbrio da água de irrigação chegou 7,7 dS $\mathrm{m}^{-1} \mathrm{e}$ a adubação nitrogenada foi $81,5 \mathrm{mg}$ de $\mathrm{N} \mathrm{kg}^{-1}$ de solo, enquanto que o maior, 67,3 capulhos,foi obtido nas plantas irrigadas com água de menor salinidade $\left(0,7 \mathrm{dS} \mathrm{m}^{-1}\right)$ e adubada

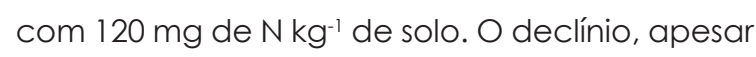
de evidenciar efeito prejudicial da salinidadena produção indica que o número de capulho colhido é promissor paraavaliação da cultura sob estresse salino. Jácome et al. (2003) trabalhando com diferentes genótipos de algodoeiro sob salinidade da água de irrigação variando de 2,0 a $10,0 \mathrm{dS} \mathrm{m}^{-1}$, também constataram perdas nos componentes de produção em reposta à salinidade da água.

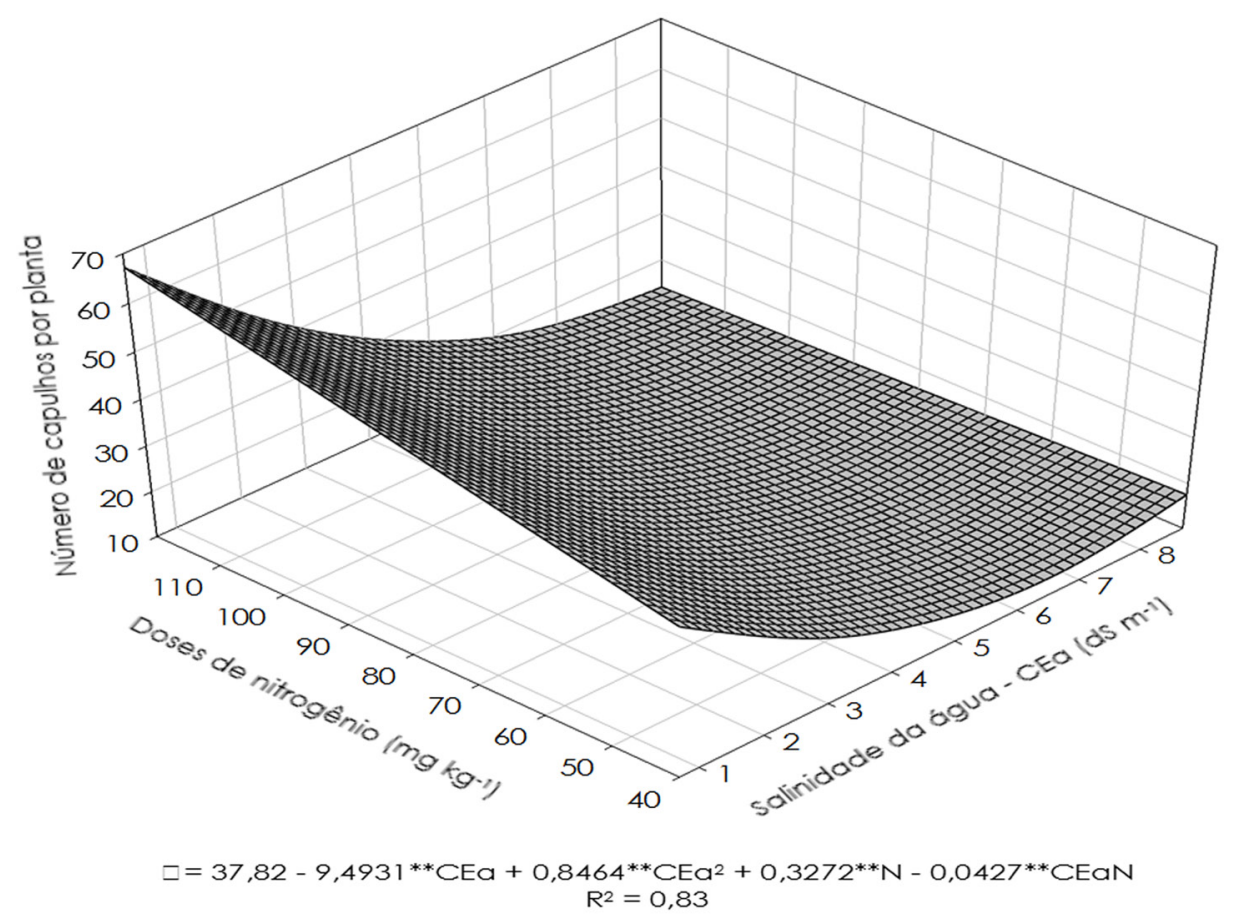

Figura 4. Número de capulho planta-1 ${ }^{-1}$ em função da interação entre salinidade da água de irrigação e doses de nitrogênio, aos 130 dias após a semeadura do algodoeiro herbáceo BRS Topázio. 
Assim como no número de capulhos, a produção por planta de algodão em caroço (Figura 5) diminuiu com o aumento do teor salino das águas e aumentou com asdoses de nitrogênio aplicadas ao solo. A maior produção de algodão em caroço por planta (327,2 g planta $^{-1}$ ) correspondeu as plantas irrigadas com água de menor salinidade $\left(0,7 \mathrm{dS} \mathrm{m}^{-1}\right)$ e adubadas com a maior dose de nitrogênio (120 $\mathrm{mg}$ de $\mathrm{N} \mathrm{kg}^{-1}$ de solo) e a menor (63,8 $\mathrm{g} \mathrm{planta}^{-1}$ ) ocorrevquando 0 ponto de equilíbrio da adubação nitrogenada atingiu $68,1 \mathrm{mg}^{\mathrm{de}} \mathrm{N} \mathrm{kg}^{-1}$ de solo e a CEa7,2dS $\mathrm{m}^{-1}$. A queda na produção de 327,2 para $63,8 \mathrm{~g}^{\text {planta }}{ }^{-1}$ ( $(80,5 \%)$ entre as plantas irrigadas com água de 0,7 e $8,7 \mathrm{dS} \mathrm{m}^{-1}$ indica que o algodoeiro BRS Topázio comportase como planta sensível à salinidade, portanto, diverge de Lopes \&Silva (2010), aoafirmarem que oalgodoeiro é tolerante à salinidade.Entretanto, estão em acordo com Oliveira et al. (2012) ao avaliarem 0 efeito da salinidade crescente da água de irrigação, de 0,5 para até 6,5 dS $\mathrm{m}^{-1}$ no crescimento e produção do algodoeiro herbáceo.

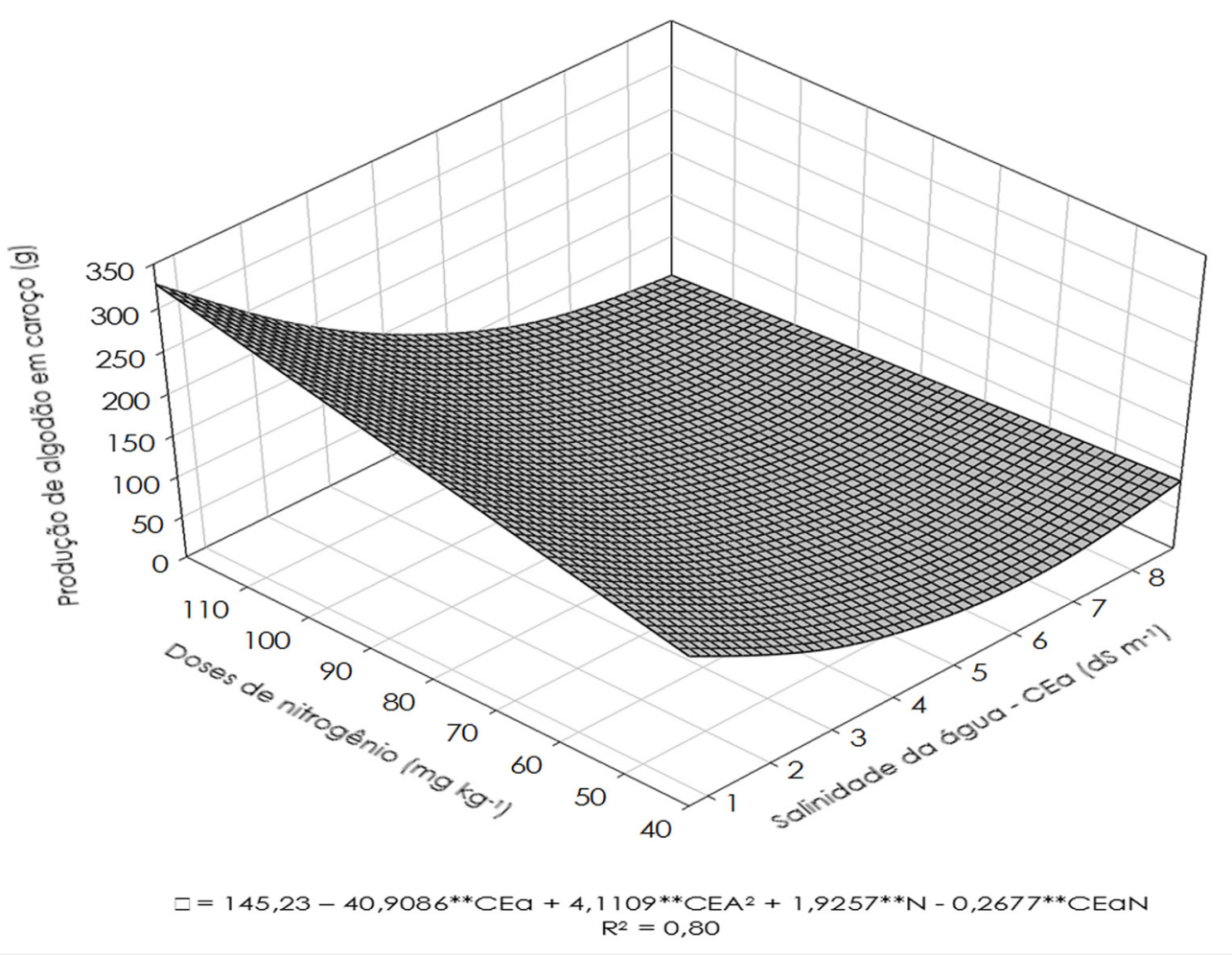

Figura 5. Produção de algodão por planta, em função da interação entre salinidade da água de irrigação e doses de nitrogênio, aos 130 dias após a semeadura do algodoeiro herbáceo BRS Topázio.

\section{Conclusões}

1. A interação entre a salinidade da água de irrigação e doses de nitrogênio não interferiu no crescimentodo algodoeiro;

2. O aumento da salinidade da água de irrigação inibiva taxa de crescimento absoluto em altura, diâmetro de caule e área foliar, sendo a área foliar a variável mais afetada;

3. O número de capulhos e a produção de algodão em caroço planta $^{-1}$ diminuiu com o aumento da salinidade da água de irrigação e aumentou com incremento da adubação nitrogenada.

\section{Agradecimentos}

Os autores agradecem ao PNPD/CAPES e INCTSal/CNPqpelo apoio financeiro para realização deste trabalho.

\section{Referências}

Amorim, A.V., Gomes-Filho, E., Bezerra, M.A., Prisco, J.T., Lacerda, C.F. 2010. Respostas fisiológicas de plantas adultas de cajueiro anão precoce à salinidade. Revista Ciência Agronômica 41: 113-121.

Benincasa, M.M.P. 2003. Análise de crescimento de plantas, Noções Básicas. 2 ed. FUNEP, Jaboticabal, Brasil. 41p. 
Chaves, L.H.G., Gheyi, H.R., Ribeiro, S. 2011. Consumo de água e eficiência do uso para cultivar de mamona paraguaçu submetida à fertilização nitrogenada. Engenharia Ambiental 8: 126-133.

Diniz, B.L.M.T., Cavalcante, L.F., Mesquita, F.O. Lima Neto, A.J., Nunes, J.C., Diniz Neto, M.A. 2013. Crescimento inicial e consumo hídrico de nim submetido ao estresse salino e biofertilizante bovino. Revista Brasileira de Ciências Agrárias 8: 470-475.

Fageria, N.K. 1989. Solos tropicais e aspectos fisiológicos das culturas. EMBRAPA-DPU, Brasília, Brasil. 425 p. (Documentos, 18).

Ferreira, D.F. 2011 . Sisvar: A computer statistical analysis system. Ciência e Agrotecnologia 35: 1039-1042.

Ferreira, P.A., Garcia, G. de O., Neves, J.C.L., Miranda, G.V., Santos, D.B. dos. 2007. Produção relativa do milho e teores folheares de nitrogênio, fósforo, enxofre e cloro em função da salinidade do solo. Revista Ciência Agronômica 38: 7-16.

Flores, P., Botella, Angeles, M., Martínez, V., Cerdá, A. 2002. Response to salinity of tomato seedlings with a split-root system: Nitrate uptake and reduction. Journal of Plant Nutrition 25: $177-$ 187.

Furtado, R.F., Mamo, A.R. de O., Alves, C.R., Freitas, S. M., Filho, S.M. 2007. Efeito da salinidade na germinação de sementes de algodão. Revista Ciência Agronômica 38: 224-227.

Jácome, A.G., Oliveira, R.H., Fernandes, P.D.E., Gonçalves, A.C.A. 2003. Comportamento produtivo de genótipos de algodão sob condições salinas. Acta Scientiarum Agronomy 25: 187-194.

Lopes, K.P., Silva, M. 2010. Salinidade na germinação de sementes de algodão colorido. Revista Verde de Agroecologia e Desenvolvimento Sustentável3: 274-279.

Maas, E.V., Hoffman, G.J. 1977. Crop salt tolerance - current assessment. Journal Irrigation and Drainage Division 103: 115 -134.

Mesquita, F.O., Cavalcante, L.F., Pereira, W.E., Rebequi, A.M., Lima Neto, A. J., Nunes, J.C. 2012. Produção de mudas de maracujazeiro amarelo submetidas à salinidade em solo com biofertilizante bovino. Ciência del Suelo 30: 31-41.

Munns, R., Tester, M. 2008. Mechanism of salinity tolerance. Annual Review of Plant Biology 59: 651-681.

Neves, A.L.R., Lacerda, C.F., Guimarães, F.V.A., Hernandez, F.F.F., Silva, F.B., Prisco, J.T., Gheyi,
H.R. 2009. Acumulação de biomassa e extração de nutrientes por plantas de feijão-de-corda irrigadas com água salina em diferentes estádios de desenvolvimento. Ciência Rural 39: 758-765.

Nobre, R.G., Gheyi, H.R., Correia, K.G., Soares, F.A.L., Andrade, L.O. de. 2010. Crescimento e floração do girassol sob estresse salino e adubação nitrogenada. Revista Ciência Agronômica 41: 358-367.

Oliveira, A.M., Oliveira, A.M.P., Dias, N.S., Medeiros, J.F. 2008. Irrigação com água salina no crescimento inicial de três cultivares de algodão. Revista Irriga 13: 467- 475.

Oliveira, de F. de A., Oliveira, F.R. de A., Campos, de M.S., Oliveira, M.K. de T., Medeiros, de J.F., Silva, O. da M. dos P. 2010. Interação entre salinidade e fontes de nitrogênio no desenvolvimento inicial da cultura do girassol. Revista Brasileira de Ciências Agrárias 5: 479 - 484.

Oliveira, F.A. de, Meneses, E.F., Arruda Filho, N.T. de, Oliveira, R.C. de, Campos, A.R.F. 2009. Tolerância de cultivares de algodoeiro herbáceo à salinidade da água de irrigação. Revista Brasileira de Oleaginosas e Fibrosas 13: 91-97.

Oliveira, F. de A. de, Medeiros, J.F. de, Oliveira, F.R.A. de, Freire, A.G., Soares, L.C. da S. 2012. Produção do algodoeiro em função da salinidade e tratamento de sementes com regulador de crescimento. Revista Ciência Agronômica 43: 279-287.

Porto Filho, F. Q., Medeiros, J.F., Gheyi, H.R., Matos, J.A., Souza, E.R., Sousa Neto, E. R. 2006. Crescimento do meloeiro irrigado com águas de diferentes salinidades. Horticultura Brasileira 24: $334-331$.

Santos, J.B. dos, Santos, D.B. dos, Azevedo, C.A.V. de, Rebequi, A.M., Cavalcante, L.F., Cavalcante, I.H.L., 2013. Comportamento morfofisiológico da mamoneira BRS Energia submetida à irrigação com água salina. Revista Brasileira de Engenharia Agrícola e Ambiental 17: 145-152.

Silva Júnior, G.S., Camara, T.R., Willadino, L.G., Martins, L.S.S., Silva, L.E. 2012. Parâmetros biométricos, nutricionais e bioquímicos em cultivares e somaclones de bananeira submetidos à salinidade. Revista de Ciência, Tecnologia e Humanidades 4: 10 - 36.

Silva Junior, S.P., Soares, F.A.L., Siqueira, E.C., Gheyi, H.R., Fernandes, P.D., Beltrão, N.E.M. 2005. Germinação, crescimento e produção do algodoeiro colorido BRS Verde sob estresse salino. Revista Brasileira Engenharia Agrícola e Ambiental 9 (suplemento): 236-241.

Siqueira, E.C., Gheyi, H.R., Beltrão, N.E.M., Soares, F.A.L., Barros Júnior, G. Cavalcanti, M.L.F. 
2005. Crescimento do algodoeiro colorido sob diferentes níveis de salinidade da água de irrigação. Revista Brasileira Engenharia Agrícola e Ambiental 9 (suplemento): 263-267.

Wendt, C.W. 1967. Use of a relationship between leaf length and leaf area to estimate the leaf area of cotton (Gossypium hirsutum L.), castor (Ricinuscommunis L.), and sorghum (Sorghum vulgare L.). AgronomyJournal 59: 484-486. 